NBER WORKING PAPER SERIES

\title{
THE ALLOCATION OF RESOURCES BY INTEREST GROUPS: LOBBYING, LITIGATION AND ADMINISTRATIVE REGULATION
}

\author{
John M. de Figueiredo \\ Rui J. P. de Figueiredo, Jr. \\ Working Paper 8981 \\ http://www.nber.org/papers/w8981 \\ NATIONAL BUREAU OF ECONOMIC RESEARCH \\ 1050 Massachusetts Avenue \\ Cambridge, MA 02138 \\ June 2002
}

The authors are indebted to Brandice Canes-Wrone, Tim Groseclose, Robert Kagan, James Snyder, Pablo Spiller, and Andrew von Nordenflycht for helpful comments and suggestions. We would also like to thank seminar participants at Harvard University, the University of California at Berkeley Conference on NonMarket Strategy, the American Political Science Association, and the American Law and Economics Association. Any flaws are solely the fault of the authors. The views expressed herein are those of the authors and not necessarily those of the National Bureau of Economic Research.

(C) 2002 by John M. de Figueiredo and Rui J. P. de Figueiredo, Jr. All rights reserved. Short sections of text, not to exceed two paragraphs, may be quoted without explicit permission provided that full credit, including (C) notice, is given to the source. 
The Allocation of Resources by Interest Groups:

Lobbying, Litigation and Administrative Regulation

John M. de Figueiredo and Rui J. P. de Figueiredo, Jr.

NBER Working Paper No. 8981

June 2002

JEL No. D7, K2, K4, L5

\begin{abstract}
One of the central concerns about American policy-making institutions is the degree to which political outcomes can be influenced by interested parties. While the literature on interest group strategies in particular institutions - legislative, administrative, and legal-is extensive, there is very little scholarship which examines how the interdependencies between institutions affects the strategies of groups. In this paper we examine in a formal theoretical model, how the opportunity to litigate administrative rulemaking in the courts affects the lobbying strategies of competing interest groups at the rulemaking stage. Using a resource-based view of group activity, we develop a number of important insights about each stage - which cannot be observed by examining each one in isolation. We demonstrate that lobbying effort responds to the ideology of the court, and the responsiveness of the court to resources. In particular, 1) as courts become more biased toward the status quo, interest group lobbying investments become smaller, and may be eliminated all together, 2) as interest groups become wealthier, they spend more on lobbying, and 3) as the responsiveness of courts to resources decreases, the effect it has on lobbying investments depends on the underlying ideology of the court.
\end{abstract}

John M. de Figueiredo

MIT

Sloan School of Management

50 Memorial Drive, E52-546

Cambridge, MA 02142-1347

and NBER

jdefig@mit.edu
Rui J. P. de Figueiredo University of California, Berkeley Haas School of Business \#1900 Berkeley, CA 94720-1900

rui@haas.berkeley.edu 


\section{Introduction}

Interest groups frequently lobby regulators to obtain favorable policy outcomes. There is a large body of scholarship which both theoretically and empirically explores the implications of the American political institutional structure on the strategies and tactics that interest groups can and do employ to influence institutional outcomes (see, e.g., Truman 1971, Schattschneider 1935, 1975; Herring 1929; Milbraith 1963; Arnold 1990; Moe 1980; Kingdon 1981; Bendor and Moe 1986; Lowi 1979; Latham 1952; Hansen 1991). The rational choice literature outlines two primary mechanisms interest groups have in the lobbying process. First, groups "buy policy" through some form of resource transfers (see, e.g., Tullock 1980; Rowley, Tollison and Tullock 1988; Stigler 1971; Snyder 1990, 1991, 1992; Strattman 1992, 1998; Groseclose 1996; Groseclose and Snyder 1996; Peltzman 1976, 1984; Becker 1983; Koford 1992). Second, groups lobby policy-makers by providing information so that policy-makers can ensure the policy they choose is close to their own preferences and those of their constituents (see, e.g., McCubbins and Schwartz 1984; Lupia and McCubbins 1994; Banks and Weingast 1992; Banks 1989; Austen-Smith 1993, 1995; Austen-Smith and Wright 1992 1994; de Figueiredo, Spiller and Urbiztondo 1999).

Unfortunately, none of these theories explicitly considers the effects that a posterior strategy - the opportunity for groups to challenge legislative or rule-making policy in court - has upon the strategies employed by groups or the outcomes of legislation and rule-making. Although a handful of authors have examined the how interest groups choose between legislation and litigation to obtain favorable policy outcomes, these papers have isolated their analysis to Congress and the courts (omitting regulatory agencies) (Rubin, Curran and Curran 
1999), or have examined the role of interest groups in affecting the composition of judges on, and cases before, the court (Caldeira and Wright 1998, McGuire and Caldeira 1993). As Olson (1990) points out, despite attempts to include interest-group litigation as part of a full-blown theory of interest groups in all institutional arenas, in most models, the analysis stops at the legislative or rule-making stage.

A second literature, alternatively, considers litigation strategies as a means of achieving policy outcomes. Riker and Weingast (1986), McNollgast (1987, 1989), McCubbins and Schwartz (1984), and Moe $(1989,1991)$ among others argue that administrative procedures and rules of standing can be used by legislators to ensure that small groups can be advantaged in administrative and legal settings. In doing so, Congress ensures that one side does not monopolize the policy-making process. Similarly, the positive literature on the courts (see, e.g. Segal and Spaeth 1993, Segal 1997, Spiller and Gely 1992; Spiller and Spitzer 1992; Cohen and Spitzer 1994; Tiller 1996; Tiller and Spiller 1999; Marks 1988; McNollgast 1994, 1997; Cross and Tiller 1998; Epstein and Knight 1995), outlines the process by which judges, modeled as political actors, render decisions in accordance with their own preferences as part of a larger inter- and intra-branch policy-making game. In these models, however, the role of the interest group has been omitted.

A third perspective on litigation examines the role of disadvantaged groups (for a summary, see Olson 1990; Epstein 1985). A number of legal scholars and political scientists have argued that litigation is a recourse for groups who are politically weak in legislative or administrative fora. Cortner (1968), for example, argues that smaller groups, "are highly dependent upon the judicial process as a means of pursuing their policy interests, usually 
because they are temporarily, or even permanently, disadvantaged in terms of their abilities to attain successfully their goals in the electoral process, within the elected political institutions or in the bureaucracy. If they are to succeed at all in the pursuit of their goals they are almost compelled to resort to litigation." This literature, however, does not develop a theory of when such strategies are likely to be effective. While they point to the importance (and even dependence) of litigation to the policy process, there is scant theoretical work which systematically explains variation in the availability and pursuit of such strategies.

Although these literatures - positive theories of lobbying, positive theories of the courts, and theories of political disadvantage - contribute a great deal to our understanding of how these strategies work by themselves, we view these as partial equilibrium theories: focussing on the relationships between lobbyists and legislators, or regulators and the courts. Our work integrates these perspectives by considering a model of lobbyists, regulators and the courts simultaneously. We ask how competing interest groups with differential resources configure their nonmarket spending over lobbying and litigation to maximize the possibility of a favorable policy outcome. This potential second stage of the fight over policy may, in turn, affect how competing groups choose the levels of their lobbying investments.

One way in which the lobbying and litigation strategies of groups is related is thatgroups must choose how to allocate resources to the first stage lobbying effort and then, should they or their opponent choose to litigate, to the subsequent litigation that might ensue. ${ }^{1}$ This is the case since as many legal and political scholars have shown outcomes in court are a function of the resources that groups bring to bear in that forum. Galantner (1974), for example, argued that the

\footnotetext{
${ }^{1}$ Resource allocation has generally been discussed in the literature on lobbying alone, and usually in the context of a collective action problem (Olson 1965, Grier, Munger, and Roberts 1994).
} 
'haves' should be advantaged in courts. While, Wheeler, Cartwright, Kagan and Friedman (1987) found little evidence for this hypothesis in state supreme courts, in most cases, litigation cannot and does not reach that level. Instead, in the lower courts, resource-intensive groups appear to have the advantage. Olson (1990), for example, finds that empirically, large groups can use federal district courts to "enforce gains" won in other fora. Similarly, Songer and Sheehan (1992) find that in the United States Courts of Appeals "upperdog litigants win much more frequently." In a resource-constrained non-market environment this suggests that there is a dependence in the choices for firms, groups, lobbyists, and public officials between vote-buying in lobbying and resources spent for litigation. We model the problem as a two-stage game. In the first stage, competing groups must allocate resources to buy policy from a regulator or agency. In the second stage, the loser in the first stage can choose to litigate. ${ }^{2}$

The primary contribution of our model is to explain the conditions under which litigation threats affect lobbying outcomes and how that informs us about the strategies employed by groups. This allows us to develop a number of insights about the nature of 'vote buying' and influence in agencies. Perhaps most importantly, our model shows that the existence of litigation can have a profound effect on lobbying. Under certain conditions, such as small differentials in

\footnotetext{
${ }^{2}$ Although we model the strategic interaction as a resource allocation problem, we do recognize that other mechanisms governing the interaction might exist as well. For example, in certain cases, the printed record from administrative lobbying has a privileged place in later adjudication, therefore implying there might (almost certainly) be an informational aspect to the relationship between lobbying and litigation. In this paper, however, we confine ourselves to the resource and policy aspects. We do this for a number of reasons. First, as noted above, a number of scholars have commented on the resource basis as being a prime dimension in which the interaction is linked. To the extent that it is useful to explore the implications of this observation more rigorously, the model is a useful device to do so. Second, given that vote-buying and rent-seeking has been perhaps the dominant approach to modelling interest group lobbying of institutional actors, it is a natural extension what such assumptions imply when we examine an integrated policy-making process across a set of sequentially linked institutions. Finally, since our interest is in using theory to identify specification for testing alternative hypotheses empirically, here we develop a model which provides testable implications which can be compared to that in an informational model. We reserve both the modelling and the testing of alternatives to other work.
} 
group resources or courts strongly predisposed toward the status quo, lobbying will completely be eliminated. Under other conditions litigation threats can actually drive policies towards traditionally advantaged groups in the rule-making stage.

This result has implications both for the political disadvantage theory and the votebuying literature. In the former case, the political disadvantage theory requires two qualifications. On the one hand, the theory is too modest: the existence of litigation not only gives smaller, politically disadvantaged groups a strategic alternative in which to obtain policy outcomes more favorable to them, but in many cases the mere threat of litigation changes policy outcomes at the rule making stage itself. On the other hand, the exact nature of advantage conferred to the 'underdogs' at the lobbying stage depends on the character of the courts. If, for example, the courts do not respond to the resources of groups, outcomes at the lobbying stage might be more extreme, rather than less extreme. The results of the model also allow us to better understand the nature of vote-buying and influence-peddling. Notably, the dependence of judicial outcomes, at least in part, on the resources conserved at that stage, mean that lobbying and litigation are partial substitutes. Money spent on one process detracts from outcomes of the other process. This introduces a strategic (and global) allocation decision between the two types of policy-making mechanisms.

Finally, the results of the model have important implications for the non-market strategies of firms. The existing literature on non-market strategy (see, e.g. Baron 1994, 1999; Krehbiel 1998) tracks the interest group literature in emphasizing who and how firms must influence regulation for non-market strategies. Our paper contributes to this understanding by pointing out the availability of litigation means that, in many cases, firms should forego lobbying 
altogether in order to ensure that any gains they obtain can be upheld and defended in the courts. As we explain in more detail below, the model suggests a number of key points of a firm's nonmarket context-how much it dislikes the status quo, the resources of its opponents, the ability to forum shop at the litigation stage, the underlying predisposition of the courts to existing policies-which will determine its best integrated lobbying-litigation strategy.

The paper proceeds as follows. In Section 2, we develop a simple model of lobbying a regulator to use as a base case to analyze the effects of litigation on policy-making. In Section 3, we allow litigation as a posterior process to lobbying by expanding the model to include a resource-responsive court which favors the status quo or court's reversion point probabilistically. ${ }^{3}$ Finally, in Section 4 , we offer a number of conclusions, including extensions of the model to be explored.

\section{A Model of Lobbying}

We start by developing a simple vote-buying model, to examine the of effects that additional institutional features might have on policy outcomes. Note, that when we consider vote-buying, we do not limit ourselves to formally buying regulators' votes through legal (campaign finance) or illegal (bribery) means. Indeed, any stock of money-metric resources which the lobbyist can transfer and which are valued by (some) regulators, can be usefully represented by these vote-buying models. This might include large budgets and facilities, subsidization of information gathering, greater jurisdiction for the agency, future expected consulting contracts, job prospects, and wealth.

${ }^{3}$ We restrict our attention here to the most interesting case, where the existing set of policies favors the smaller group. 
The lobbying game has three players: a representative regulator or government agency $R$, which is issuing orders, making rules, or implementing regulations; and two interest groups or lobbyists, $A$ and $B$. Each of the interest groups is endowed with a stock of resources $w_{i}, i 0 \in A, B>$ Each player has single-peaked preferences over policies in a uni-dimensional policy space $x$ Uú, where a player's utility is characterized by a maximum or ideal point at $x_{i} i 0 \in A, B, R>$ The regulator's utility function, is assumed to take the form:

$$
U_{R}^{\prime} \&|x| \%
$$

where $x$ is the policy that is implemented, and $y$ is the total transfers which are made to $R$. Notice that this specification of $R$ 's utility function implies, without loss of generality, that $x_{R}{ }^{\prime} 0$. The two interest group lobbyists each have utility functions specified as follows:

$$
U_{i}^{\prime} \&\left|x \& x_{i}\right|
$$

Further, to create a tension between the interests of the lobbyists, we assume $x_{B}<0<x_{A}$. Notice that this specification of preferences means that the lobbyists' resources are such that they must either 'use it or lose it:' they expend no costs to transfer resources to $R$, and they do not retain any of these resources for private consumption at the end of the game. ${ }^{4}$ Finally, we make some assumptions about the endowments of the lobbyists. In particular, we assume $w_{i}<\left|x_{i}\right|$ and $w_{A} \$ w_{B}$. The former means that the budget constraint will always bind the offers of the lobbyists. The latter simply means that one of the groups, in particular $A$, has greater resources than the other.

The sequence of moves (summarized in Figure 1) is as follows. $A$ and $B$ simultaneously announce an offer to $R$, which consist of a policy offer $x_{i}^{o}$, and a transfer $y_{i} \# w_{i}$. After these

\footnotetext{
${ }^{4}$ Left over resources only means that the constraints are less binding and do not add much insight to the theory.
} 
announcements, $R$ then chooses one of three options. She can accept $A$ 's offer, $B$ 's offer, or neither, and implement a policy anywhere in $x$. Finally, after $R$ has chosen her action, policies are implemented according to $R$ 's choice, transfers are effected, payoffs are made and the game

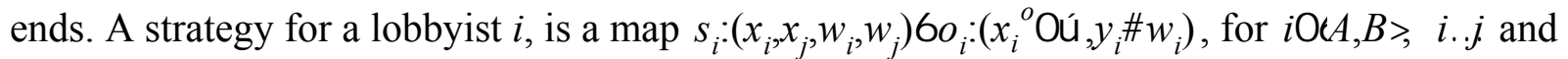
where $o_{i}$ denotes the policy-transfer pair offered by $i$. Thus, a lobbyist's strategy is simply his announcement which states his take-it-or-leave it offer to $R$ of a transfer of $y_{i}$, in exchange for the regulator's implementation of policy $x_{i}^{o}$. Similarly, a strategy for $R$ is a map $s_{L}:\left(o_{A}, o_{B}, x_{A}, x_{B}, w_{A}, w_{B}\right) 6 x 06 x_{A}^{o}, x_{B}^{o}, x 0 u$ r $>$ In this case, $R$ 's strategy is simply a choice from the two offers made by $A$ and $B$, or her refusal of both and implementation of some other policy in the policy space $x$.

[FIGURE 1 about here]

To find the equilibrium strategies of the players, given the parameters of the model, we use the concept of Nash subgame perfection. This means that every player plays an optimal or expected utility maximizing strategy forward at each point, given that they have reached that point. ${ }^{5}$ Given this solution concept, we have the following proposition (all proofs are contained in the appendix):

\footnotetext{
5 Note that we assume in the case of a 'tie' that $R$ will choose the policy of the largest lobbyist. This assumption is justified because as will be noted in the proof, the smaller player simply constrains the largest player be his best offer-he can do no more. So the larger player can always move his policy-offer an $\varepsilon$ amount towards zero, making his offer the one $R$ accepts.
} 
PROPOSITION 1. The following constitutes a subgame perfect Nash equilibrium to the lobbying game:

$$
\begin{aligned}
& \text { i. } s_{A}:\left(x_{A}^{o(1} w_{A} \& w_{B}, y_{B}^{(1} w_{A}\right) \\
& \text { ii. } \mathrm{s}_{B}:\left(x_{B}^{o(1} 0, y_{B}^{(1} w_{B}\right) \\
& \text { iii. } \mathrm{s}_{R}: \quad \mathrm{x}_{A}^{o} \text { if } y_{A} \&\left|x_{A}^{o}\right| \$ y_{B} \&\left|x_{B}^{o}\right| \text { and } \mathrm{y}_{A} \&\left|x_{A}^{o}\right| \$ 0 \\
& \mathrm{x}_{B}^{o} \text { if } y_{A} \&\left|x_{A}^{o}\right|<y_{B} \&\left|x_{B}^{o}\right| \text { and } \mathrm{y}_{B} \&\left|x_{B}^{o}\right| \$ 0
\end{aligned}
$$

0 otherwise.

Consider the parts of Proposition 1 in reverse order. $R$ 's strategy is clear. If she chooses not to accept either offer from the interest groups, the best outcome that she can obtain is to implement her ideal point, $x=0$, which will generate a utility for $R$ equal to zero. This therefore establishes her reservation value for any offer made by one of the interest groups. Further, for every offer that $B$, the smaller interest group makes, $A$ can beat it, since it has greater resources. To see this, suppose $B$ makes an offer of $x$ and offers $R$ all of its endowment $\mathrm{w}_{B}$. $A$ can always beat that offer by offering $w_{A}$ and an $x$ that is (slightly) closer to $x_{A}$ than $B$ 's offer. As long as the policy offer is not 'too far' from $B$ 's offer in its distance from zero the regulator will accept it. Since $B$ can never win, it will make the best offer it can to $R$ in order to temper $A$ 's offer. What is that offer? In this case, it is all of its endowment and a policy of 0 . Given this offer by $B$, $A$ will use all of its resources in excess of $w_{B}$ to pull the policy back toward her own ideal point. In particular (see Figure 2), it will make a policy offer of $w_{A} \& w_{B}$, which, when combined with a transfer of its full endowment will be equivalent to $B$ 's offer to the regulator. Finally, it will always be in both players' interests to use their full endowment; since they get no (dis)utility from spending their full endowment, it is a weakly dominant strategy to spend all of it.

[FIGURE 2 about here] 
Proposition 1 contains a number of important features of the process of (vote-buying) lobbying. First, the larger player's offer, in this case $A$ 's, is always accepted. The reason for this is precisely the explanation of the equilibrium solution above: the larger player can always outspend the smaller player and get a better outcome than he could either in the absence of lobbying or under $B$ 's best offer. So the availability of vote-buying biases policy outcomes towards the larger player (in other words, $x^{(}>0$ ).

Second, despite this bias, the smaller player plays an important role. By making her best offer, the smaller player puts a bound on how far the larger player can go in requesting policy. In this sense, $B$ 's offer puts a constraint on $A$ 's offer and thus replaces the constraint of $R$ 's reservation level. Notably, the smaller the difference in endowments-in other words, as the relative size of $A$ versus $B$ decreases, the closer equilibrium policy outcomes $x^{*}$ move toward

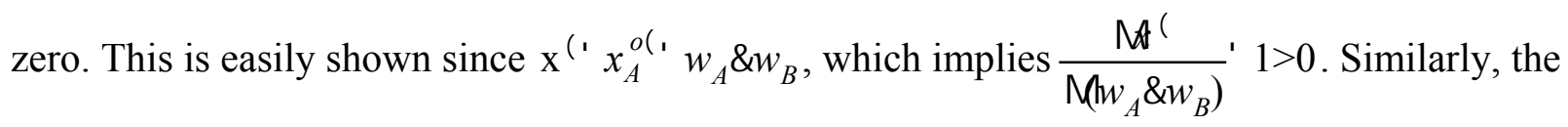
equilibrium policy outcome is continuous in the difference in endowments. As the difference gets larger, the policy becomes more and more positive. ${ }^{6}$

Third, the regulator is strictly better off by the existence of a second group. To see this compare $R$ 's utility with and without the presence of a second interest group (or alternatively, if $\left.w_{B}^{\prime} 0\right)$. In this case, $x^{('} w_{A} \mathrm{Y} U_{R}^{(1} \& w_{A} \% v_{A}{ }^{\prime} 0$. When $w_{B}>0$, the regulator's utility is $\mathrm{U}_{R}{ }^{\prime} \&\left(w_{A} \& w_{B}\right) \% w_{A}{ }^{\prime} w_{B}>0$. Further, the degree to which she is better off is increasing in the size of the smaller group: as the groups become more and more balanced, $R$ 's rents go up linearly. In

\footnotetext{
${ }^{6}$ In this sense, the outcome has a similar property to Tullock's rent-seeking model and its variants. However, the method of obtaining such a result is different here. Tullock's (1980) model, each player can affect the probability of obtaining the rents, whereas in this case, there is no uncertainty-the result is generated by the structure of the auction in the game: a single offer which is take or it leave it. The model also shares the continuity property with Snyder (1991) in which he shows how vote-buying cartels can influence policy outcomes. Again, Snyder's model is more general in that he develops the models using a distribution of voters on a continuum.
} 
this sense, the lobbying model has the same property seen in other models of competitive lobbying in which the existence of (strong) competitive groups, irrespective of the policy position of $R$, generates rents for the regulator (see, for example, de Figueiredo, Spiller, and Urbiztondo 1999, Austen-Smith and Wright 1992, Lupia and McCubbins 1994).

\section{The Effects of Litigation on Lobbying and Policies}

The lobbying game gives a simple understanding of how competitive vote-buying operates. Using these results, we turn to an analysis of the effects that litigation, or at least the existence of an opportunity for parties to litigate, has on the allocation of resources to lobbying and equilibrium policy outcomes.

In order to conduct this analysis, we append the litigation game to the lobbying game. The players and their preferences are identical to those in the lobbying game, except that we add a non-strategic player, the courts. We make two primary assumptions about how litigation operates. First, if the policy produced at the lobbying stage is overturned by the courts, the final policy outcome is the court's reversion point, which in many cases can be interpreted to be the status quo. This feature, a standard assumption in much of the formal literature on the courts (see e.g., Canes (1998), Eskridge and Ferejohn (1994), and Ferejohn and Shipan (1989)), captures the nature of many classes of litigation outcomes. ${ }^{7}$ Second, following our earlier explication of the empirical analysis on winners and losers in the courts, we assume that the outcome at the

\footnotetext{
${ }^{7}$ For example, in telecommunications, the FCC is issuing a series of non-adjudicatory general orders about entry of local companies into long distance. The entry variable is dichotomous. de Figueiredo (1997) examines the telecommunications sector and finds that many cases have dichotomous, mutually exclusive outcomes. For example, in adjudication, the Federal Communications Commission makes a ruling as to who will be awarded the license. The court can then uphold the FCC or overturn the FCC. It is extremely difficult, and never the case in fact, that the license is split among two or more corporations. This represents $50 \%$ of FCC litigated cases. Canes (1998) finds similar circumstances at the Environmental Protection Agency in permits for development in wetlands.
} 
litigation stage is (somewhat) dependent on the resources that groups spend at that stage. We think of this not as judge-bribing, but more as the quality and quantity of legal resources acquired. For example, more money translates into better expert witnesses and better lawyers.

The sequence of play in the litigation game is summarized in Figure 3. After the lobbying game, each of the interest groups has an option to initiate litigation. Their choice is indicated by the indicator variable $\mathrm{k}_{i} \mathrm{O} 0,1>$ where $k_{i}^{\prime} 1$ if litigation is initiated and zero otherwise. Next, both interest groups simultaneously choose an amount of resources $z_{i}$ to spend on litigation, subject to the constraint that they cannot spend more than the remainder of their endowment after the lobbying stage, i.e. $z_{i} \# w_{i} \& y_{i}$.

In the next move, the court decides to either overturn the decision of the regulator, in which case the policy implemented reverts to the status quo which is $q$ Oú, or to uphold the regulation in which case the outcome is $x_{p} \cdot{ }^{8}$ We assume this probability is weakly increasing in the net amount of resources expended on litigation by the groups. To provide analytic clarity, we model this assumption by positing that the probability that the court overturns the decision is $\left.\Phi\left(\alpha \% z_{i} \& z_{j}\right)\right)$ where $\Phi($.$) is the standard normal cumulative density function z_{i}$ is the amount of resources spent by the initiator to defend the status quo, $z_{j}$ is the amount of resources spent by the other group to defend $x_{p}, \alpha$ is a measure of the "bias" of the court toward the status quo, and $\beta \$ 0$ is a measure of the responsiveness of the court to resources. After the choice by the court, the final policy is implemented, transfers are effected and payoffs made.

\footnotetext{
${ }^{8}$ Although we call this point a status quo, and will follow that line of description throughout the ensuing discussion, in fact, this point more generally would represent the court's reversion point. In many cases, the courts will have both formal and ractical difficulty implementing any other point (in other words, they make their ruling under a 'closed' rule), so the status quo interpretation seems most natural.
} 
A number of points are worth noting about this specification for the role of the courts. First, the courts in our model can be interpreted as "political." In "standard" positive political theory models of the courts, courts are motivated by policy outcomes (see, e.g. Tiller 1996, 1999). As a veto point, they can act on these preferences by imposing the status quo as a reversion point if the policy passed in earlier policy-making stages makes them worse off. In these models, therefore, there is a constrained set of outcomes (which is the set of policies that the courts prefer to the status quo) that are feasible in the earlier policy-making stages, and players will optimize the choice of policy within this constrained set. In our model, the courts can also be interpreted as having policy preferences. In this case, the underlying probability that the court will uphold the status quo represents the degree of "bias" in favor of existing policy. As noted earlier, the parameter $\alpha$ reflects the degree of bias. Thus, as in the more standard models, in our model, the status quo bias of the court constrains the set of policy choices in rulemaking. There are some important differences, however. First, unlike previous models, we do not make this status quo bias a function of the policy choice at the rulemaking stage; in other words, $\alpha$ is not a function of $x$. While this would complicate the analysis substantially, it would not change the substantive results we outline later. Second, our model provides a more flexible and natural way to analyze resource-responsive courts, as it does not limit the court to a rent-seeking veto player but can also be interpreted to respond to the quality and intensity of the arguments.

Another important, and related, point is that although we model the courts as nonstrategic, an alternative interpretation is that the courts are acting strategically, but that their preferences are unknown. In this interpretation, a strategic court will act deterministically based on the outcome of the rulemaking stage: they will only overturn policies which make it worse off 
than the status quo. But the location of the courts will be uncertain to players moving earlier. Thus, the other players' expectations about the future move of the court will depend on their beliefs about the location of the court. ${ }^{9}$ In this manner, when combined with the previous point, our specification of the lobbying-litigation game can be seen as one in which there are political and strategic courts, but in which the courts' precise preferences are not known to either interest groups or regulators.

A third point which is important to note is that in many cases of administrative rulemaking, the regulator has the option to "keep the gates closed." In other words, if they are fearful that the courts will lead them to a worse outcome, they can choose not to allow the courts to rule on any policy by simply making no change. ${ }^{10}$ In our model, the regulator has to choose a policy, meaning that strictly speaking, there is no gatekeeping power. However, since the regulator can never do worse than the status quo-in other words, since the court can at most implement the status quo-the regulator (and the winning interest group) will never be worse off and would, even if given a choice of gatekeeping, never keep the gates closed.

Finally, in the setup of our model, the resources spent at the litigation stage are by the interest groups. In practice, however, the government agency is the defendant when a group that has standing initiates litigation against the agency ruling. This means that when litigation is possible, part of the transfer goes via the agency, as a subsidy or tax by the agency in anticipation of litigation. This interpretation introduces a complication, since the amount of

\footnotetext{
${ }^{9}$ That a court's exact status quo bias is unknown could be generated by a number of real-world aspects of the process including panel selection, issue-specific preferences of judges and temporal shocks to preferences.

${ }^{10}$ Of course, this is not always the case. In many cases, Congress specifically requires that an administrative agency determine a rule. The well-documented case in which Congress required the FCC to establish a standard for the automation and integration of household electronic devices under the 1992 Cable Act is a prime example. (Baron 1994)
} 
resources the agency will want to expend on defending the new rule might be different than the optimal choice by the interest grup that wins at the lobbying stage. This problem, however, is obviated however in our assumption that the actions of the agency is able to commit to actions (both policies and litigation strategies) after the lobbying stage.

[FIGURE 3 about here]

To begin our analysis of the game, consider first the litigation stage. A player will initiate litigation if and only if, after the lobbying stage, they are made better off if the status quo prevails as the final outcome $x$. Thus a player will initiate litigation when

$$
\left|q \& x_{i}\right|<\left|x_{p} \& x_{i}\right| \quad i 0(A, B>
$$

Further, if $q 0\left[x_{B}, x_{A}\right]$, one of the two players will always initiate litigation and will use all of her remaining resources to overturn $x_{p}$ while the other player will conversely spend all of her remaining sources to defend $x_{p}$. The reason is that no matter what the choice of the regulator, one side is always better off with the status quo. We formalize this logic in Lemma 1.

LeMMA 1. Suppose ${ }_{q} \mathrm{O}\left[x_{B}, x_{A}\right], x_{p} \mathrm{O}\left[x_{B}, x_{A}\right]$, then if $\mathrm{x}_{p}>q, B$ will initiate litigation, use all of her remaining resources $w_{B} \& y_{B}$ to overturn the new policy $x_{p}$, and $A$ will use all of her remaining resources $w_{A} \& y_{A}$ to defend the new policy. If $x_{p} \# q$, A will initiate litigation otherwise, $A$ will use all of her remaining resources to overturn the new policy and $B$ will use all of her remaining resources to defend the new policy. 
Now we turn to analysis of the equilibrium. To simplify the analysis and capture basic intuitions, we analyze perhaps the most interesting case in which ex ante lobbying policy power is given to the disadvantaged group. In particular, we assume $q 0\left(x_{B}, 0\right)$ and $w_{B}{ }^{\prime} 0$. The former assumption simply states that the status quo is on the smaller players' side of the regulator.. which means we candirectly address the conditions under which the political disadvantage theory is most relevant. The second simply means that the smaller players' only recourse is to litigation, again, consistent with the political disadvantage theory. In this case, by Lemma 1, $B$ is always the plaintiff in the litigation stage.

LemMA 2. Suppose $\mathrm{q} 0\left(x_{B}, 0\right)$ and $\mathrm{w}_{B}{ }^{\prime} 0$, then $\mathrm{x}_{A}^{o} \$ 0, \mathrm{x}_{p} \$ 0$, and $B$ will always litigate in equilibrium.

Lemma 2 states that policy offers from $A$ and the policy outcome during the lobbying stage will always be weakly to $A$ 's side of $R$. To see this, note that $B$ will never be able to offer $R$ a policy that $R$ will accept since $B$ has no resources to offer in exchange. Thus, to simplify the notation, from now on we drop the subscripts on $x_{A}^{o}, w_{A}$, and $y_{A}$. Next, notice that $R$ will always be better off from a lottery over zero and $q$, rather than a lottery over any other $x$ and $q$, so even if $R$ rejects $A$ 's offer, $R$ will implement zero. As before, then, this strategy conditions $A$ 's strategy. Consider first whether $A$ will ever offer $x^{\circ}<0$. Given Lemmas 1 and 2, one of the players will always have an incentive to litigate, so $A$ will always be better off saving her resources to at least defend zero rather than spending resources to get $R$ to move closer to $x_{B}$. If $A$ does make an offer, therefore, it will always be one which makes her better off than zero. Thus, in equilibrium, lobbying results will again always be biased toward the larger group. 
Given this result, it is possible to analyze the outcomes of the lobbying game. Consider first the regulator's strategy. $R$ will accept an offer from $A o^{\prime}\left(x^{o}, y\right)$ if and only if:

$$
\Phi(\alpha \%(y \& w)) q \&(1 \& \Phi(\alpha \%(y \& w))) x^{o \%} \% \Phi(\alpha \& \beta w) q .^{11}
$$

If $R$ accepts $A$ 's offer, her expected payoff is the quantity on the left-hand side of (2a). The first term is the probability that the new policy will be overturned multiplied by the disutility to $R$ of the status quo. The second term is the probability that the new policy will be upheld multiplied by the disutility suffered by $R$ from the policy implemented in the lobbying stage. Note that both of these probabilities are a function of the transfers in the lobbying stage. The third term is simply the transfers $A$ makes to $R$ if $R$ accepts $A$ 's offer. The right-hand side is the expected utility for $R$ if she rejects $A$ 's proposal-she obtains the status quo with some (smaller) probability and otherwise gets her ideal point. (2a) can be rewritten:

$$
\left.y>\left(\Phi_{0} \& \Phi_{1}\right) q \% 1 \& \Phi_{1}\right) x^{o}
$$

where $\Phi_{1}{ }^{\prime} \Phi(\alpha \% \phi(y \& w))$ and $\Phi_{0}{ }^{\prime} \Phi(\alpha \& \beta w)$. So $R$ will accept the offer only if the benefit she gets from the transfer outweighs two types of cost. On the one hand, by accepting $y$ the chance that the outcome will be $q$ increases. On the other hand, the offer that $A$ makes to $R$ will also be weakly worse (by Lemma 2), and thus imposes a cost on $R$ if she accepts the offer.

Given this result, we can write down $A$ 's problem at the lobbying stage:

${ }^{11}$ It is worth noting that (2a) is written using the fact that the negation of the absolute value of a negative number $k$ is simply $k$. So $\& \Phi(\alpha \%(y \& w))|q| \&(1 \& \Phi(\alpha \%(y \& w)))\left|x^{o}\right| \%>\& \Phi(\alpha \& \beta w)|q|$ can be written as in (2a) using the fact that $q<0$ and $x \% \%>0$. 


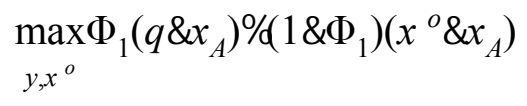

s. t. (i) $\left.y>\left(\Phi_{0} \& \Phi_{1}\right) q \% 1 \& \Phi_{1}\right) x^{o}$

(ii) $0 \# x^{\circ} \# x_{A}$

(iii) $0 \# y+\#$

$A$ chooses her offer maximizing the expected utility subject to $R$ 's acceptance. ${ }^{12}$ If $R$ will not accept an offer that makes $A$ better off than no transfer and $x_{p}{ }^{\prime} 0$, then $A$ will simply offer nothing and no exchange will take place. Solving this maximization problem for an interior solution, we have:

PROPOSITION 2. If the wealth differential between $A$ and $B$ is not too large, and $C$ is sufficiently responsive to resources, then the following constitute equilibrium policy offers, proposals and regulation in the lobbying stage:

(i) $\mathrm{s}_{L}:$ Reject $o_{B}$ Accepto $_{A}$ if $\left.y>\left(\Phi_{0} \& \Phi_{1}\right) q \% 1 \& \Phi_{1}\right) x^{o}$

0 otherwise

(ii) $B: o_{B}{ }^{\prime}\left(x_{B}^{o}<0, y_{B}{ }^{\prime} 0\right)$

(iii) $A: y^{\prime} w \& \frac{\alpha}{\beta} \& \frac{1}{\beta} \sqrt{\log k^{2}}$

$$
x^{o \cdot} \frac{\left(\Phi_{3} \& \Phi_{2}\right) q \& \frac{\alpha}{\beta} \& \frac{1}{\beta} \sqrt{\log k^{2}} \% v}{1 \& \Phi_{3}}
$$

where $\mathrm{k}^{\prime} \frac{2 q \beta}{\sqrt{2 \pi}}, \Phi_{3}{ }^{\prime} \Phi\left(\& \sqrt{\log k^{2}}\right)$, and $\Phi_{2}{ }^{\prime} \Phi\left(\alpha \& \beta w_{A}\right)$. Further, an equilibrium policy outcome from the lobbying stage will be $x_{p}^{(1} x^{o(} \cdot{ }^{13}$

We begin our interpretation of this equilibrium by first commenting on the conditions. The court's being sufficiently responsive guarantees that the equilibrium solutions will be real-

\footnotetext{
${ }^{12}$ Note that $œ<b,|a \& b|^{\prime} b \& a$.

${ }^{13}$ Note that the equilibrium explicated here is not necessarily unique.
} 
valued. The wealth differential not being too large guarantees an interior solution. In other words, relative to the extremity of the group and the reversion point, the group's endowment is not overwhelming. It also implies that there must be a sufficiently large chance that the court will overturn the outcome of the lobbying stage (i.e. $\alpha$ can not be "too small"). The proof in the appendix lays out these conditions more formally.

The equilibrium stated in Proposition 2 has a number of implications for the nature of lobbying in the shadow of litigation. First, the existence of litigation can bias the outcome of lobbying either closer or farther from the winning group, depending on the parameter values. The reason for this is that the existence of litigation has two effects on the policy and transfer offers that $A$ makes. The first effect is that litigation relaxes the constraint that $R$ 's reversion point places on the interest group. Whereas in the pure lobbying game the regulator knows she will obtain a final policy outcome of zero with certainty, with litigation, even if she rejects $A$ 's offer, the best she can obtain is a lottery over zero and $q$. Thus, by passing regulation that will be less favorable, she only bears part of the cost, whereas she obtains the transfer in the same amount as before. ${ }^{14}$ This allows the interest group to demand a more favorable policy than in the absence of the chance of overturning the regulation. However, the second effect is driven by the fact that the probability of obtaining the court's reversion point is a function of the amount of resources $A$ has left, thus both $R$ and $A$ have incentives to encourage $A$ to conserve resources to

\footnotetext{
14 To see this more clearly, consider a one-interest group lobbying game analogous to the form in section 2 (i.e. $w<|x|, x>0$ ) in which there is some fixed probability $\gamma$ that the regulation will be overturned and result in $q<0$. In this case, we can write the interest group's problem as

$$
\left.\max _{o, y} \gamma(q \& x) \% 1 \& y\right)\left(x^{o} \& x\right) \quad \text { s.t. (i) } \&(1 \& y) x^{o \%} \%>0 \quad \text { (ii) } y \# w
$$

which has the unique solution in which the group will offer to transfer all of its endowment in exchange for a policy of $\frac{w}{1 f}$ if $\frac{w}{1 \&}<x$ and $x$ otherwise, and its offer will be accepted. Notice that the equilibrium policy in this case is stritfly higher (and therefore closer to the group's ideal point) than in the absence of litigation.
} 
defend against the court's reversion point in the litigation phase. The more of her endowment that the lobbyist transfers to the regulator at the lobbying stage, the more likely it is that the final outcome will be the court's reversion point, and the lobbying efforts will be wasted. So the lobbyist has an incentive to save money and offer less. Similarly, even if the lobbyist has a strong incentive to transfer a large portion of its endowment to the regulator, the regulator, depending on the extremity of the court's reversion point, might also not want the lobbyist to do so, since she obtains a positive externality in the litigation stage from the remainder of the lobbyist's endowment, as well - the more of it that is left, the greater the chance that the outcome of the regulation stage will stand.

In terms of the equilibrium policy that the regulator passes, then, this downward pressure on the transfer also puts downward pressure on the lobbyist's policy offer, since the smaller the transfer, the less extreme a policy the regulator is willing to give in exchange. So whereas the existence of some probability of overturning the regulation relaxes the constraint on the policy proposal that the lobbyist can make for a given transfer, the incentive of both the lobbyist and regulator to save resources for the litigation phase puts downward pressure on the transfer and therefore the policy offer that the lobbyist can make. The first implication is that the net of these two effects - whether the final policy outcome from the lobbying stage is closer or farther from the lobbyist's ideal point in comparison to the game in the absence of litigation-depends on the other parameter values, which we now consider. ${ }^{15}$

The next set of related results examines the comparative statics of the equilibrium transfer and policy. To analyze these comparative statics, we first employ the following result.

\footnotetext{
${ }^{15}$ Of course, in expectation, even if the lobbying policy goes up, the expected final policy might make the smaller group better off in comparison tho the case when litigation is unavailable.
} 
Corollary 1. Suppose $\mathrm{qO}\left(x_{B}, 0\right)$ and $\mathrm{w}_{B}{ }^{\prime} 0$, and conditions (i) and (ii) of Proposition 2 hold, if $\mathrm{y}^{(}$increases, $x^{0^{*}}$ increases.

The logic of this result is straightforward. Fixing all of the parameter values, anything which increases the equilibrium offer will allow the lobbyist to demand a higher (better) policy at the lobbying stage.

Using Corollary 1, then, we derive a second implication of Proposition 2: as the court's reversion point becomes more extreme, the transfer made in the lobbying stage is smaller, and therefore the regulation passed moves away from the lobbyist. To see this, consider the first derivatives of $y^{(}$and $x^{o^{*}}$ with respect to $q$ :

$$
\left.\frac{M(}{M}\right)^{\prime} \& \frac{1}{\beta q \sqrt{\log k^{2}}}>0 Y \frac{M^{o l}}{M}>0
$$

Consider the effect of $q$ on the proposals that the lobbyist can make. If $q$ is extreme, then the lobbyist wants to save money in order to defend against the court's reversion point. Similarly, the regulator also wants the lobbyist to save money in order to defend against a more extreme court's reversion point. In this case, the lobbyist will not transfer as much to the regulator and then, by Corollary 1, will not be able to obtain as favorable regulation.

A third implication of Proposition 2 is that as the endowed interest group's resources increase, the transfers are higher and the outcome of the lobbying stage is closer to her ideal point. Again, consider the first derivatives of $\mathrm{y}^{(}$and $x^{o^{*}}$ with respect to the parameter $w$. Here, we have:

$$
\frac{M(1}{M v} 1 Y \frac{M^{o l}}{M v}>0
$$


Again, the logic is straightforward: as the interest group gets larger and larger, it is relatively more able to transfer resources to the regulator without sacrificing the benefit of saving. Of course, it is not the case that it will transfer all incremental resources; instead part will go towards improving its position in the lobbying stage and part will be conserved in order to resist the court's reversion point in the litigation stage.

A fourth implication of Proposition 2 is that as the underlying probability that the court will overturn the decision increases, the transfers decrease, and therefore lobbying outcomes are driven towards non-results. In the extreme, as this probability increases, it can lead to the elimination of lobbying altogether. Again, consider the first derivatives of $\mathrm{y}^{(}$and $x^{o^{*}}$ with respect to the parameter $\alpha$ :

$$
\frac{\mathrm{M}\left({ }^{\prime}\right.}{\mathrm{M} \alpha} \& \frac{1}{\beta} \mathrm{Y} \frac{\mathrm{M}^{o(}}{\mathrm{M} \alpha}<0 .
$$

Here the logic is not as straightforward. If the probability of a court overturning an agency is higher, why would that effect the outcome at the lobbying stage? The answer can best be seen by considering how the probability of obtaining the court's reversion point responds to changes in $y$ as $\alpha$ increases. When $\alpha$ increases, it becomes increasingly costly for both the lobbyist and the regulator-in terms of the probability that the new policy will be overturned-for the lobbyist to transfer $y$ to the regulator. This effect outweighs the effect of relaxation of $R$ 's reservation constraint since it enters linearly. As the 'locus' of the distribution shifts downward, the transfers and the policies proposed by the regulator tend toward zero-in other words, in the 
extreme, the existence of litigation can completely eliminate lobbying if the underlying probability of the regulation being overturned is sufficiently high.

A final implication of Proposition 2 is that the equilibrium transfers and policy can be non-linear in $\beta$ (the responsiveness of the courts to resources) depending on $\alpha$. Recall that when $\beta$ is high, the courts are more responsive to resources than when $\beta$ is low. That is, when $\beta$ is very high, the probability of being overturned changes quickly from almost zero to almost one. When $\beta$ is low, the policy responds very little, and the probability is essentially independent of resources. When $\beta$ is somewhere in between, it rises regularly in a more linear fashion. The effect of this pattern of responsiveness on the equilibrium can be seen by examining the first derivatives of $y^{\prime}$ and $x^{o l}$ :

$$
\frac{M(1}{M B} \cdot \frac{1}{\beta^{2}}\left(\log k^{2} \% \sqrt{\log k^{2}} \& 1\right) \underset{<}{<} 0 \frac{M^{o l}}{M B} \geq 0
$$

Here it is clear that the effect of $\beta$ on the equilibrium transfers and policy depends on $\alpha$. Figure 4 illustrates the effect of two different $\alpha$ s on the comparative statics of $y^{\prime}$ and $x^{o l}$ with respect to $\beta$. When $\alpha$ is very low, the equilibrium transfers as $\beta$ increases will be muted until $\beta$ becomes very large (in other words, $y^{*}$ will be convex in $\beta$ ). Alternatively, when $\alpha$ is large, as the courts become increasingly responsive to resources, $y^{\prime}$ and $x^{o l}$ become more and more extreme. The reason for this is that as $\beta$ increases, it "pulls out" the area in which the probability of being overturned is very low and therefore relaxes the concern that the lobbyist and the regulator have about risking increasing chances of the court's reversion point with more spending. 
Finally, it is worthwile considering an extension to the model: the effects of delay. An important strategy for a losing interest group is to initiate legal action-even if they know they might eventually lose-in order to delay the implementation of a new policy which is less favorable to the group than he status quo. Indeed, this strategy interacts with the resource aspects of litigation strategies, as plaintiffs that are more resource-rich will likely be able to delay the implementation longer than those groups which are resource-poor. If this is the case, what effect would the opportunity to delay have on the model we examine? In this case, if litigation is used in part to delay, it will only complement our results in the same direction already obtained. Because the groups will still treat lobbying and litigation as partial substitutes: money will be conserved at the lobbying stage in order to obtain faster (slower) results at the litigation stage. ${ }^{16}$ In this sense, then, our results will still hold in the extreme case in which there is no uncertainty about the final outcome of litigation but there is about the timing of the decision.

[FIGURE 4 about here]

These results, then, illustrate that under certain conditions, litigation can have a dramatic effect on lobbying. In cases when the court's reversion point favors a smaller group - the focus of the political disadvantage theory. The results show that results in both the positive literature on vote-buying and the political disadvantage theory have to be qualified: based on the characteristics of the courts' decision-making, the existence of litigation dramatically alters the

\footnotetext{
${ }^{16}$ While a detailed formalization of this point is beyond the scope of this paper, such a model is available from the authors.
} 
nature of lobbying in the earlier stages.

\section{Concluding Discussion}

Although scholars have examined lobbying and litigation in isolation, we have developed a theory to take account of the linkages between the regulatory and litigatory strategies by interest groups. In developing this integrated theory, the paper demonstrates not only how resource-responsive courts introduce a dependence between lobbying and litigation strategies, but also provides explicit conditions under which such strategies will be pursued, and further, how those strategies influence both intermediate and final outcomes in the policy process. We develop a model that explains how competing interest groups lobby for policy in the absence of litigation. Then we show that by permitting litigation of regulatory rules, as is common in the United States, lobbying strategies are changed. We show that courts, even if relatively inactive, can have a profound effect on the amount of lobbying that occurs. In particular, we demonstrate that 1) as the court's reversion point becomes more extreme, the transfer made in the lobbying stage will be smaller; 2) as the endowed interest group's resources increase, the transfers are higher and the outcome of the lobbying stage is closer to the its ideal point; 3) as the underlying probability that the court will overturn the decision increases, the transfers to the regulator decreases, and therefore lobbying outcomes are driven toward non-results, and this effect may eliminate lobbying altogether; and 4) as the responsiveness of the court to resources changes, the effect it has on lobbying will depend upon the ideology of the court. The theory, thus, provides insights and qualifications to the existing literatures on interest groups, lobbying, legal challenges, political disadvantage, and non-market strategy, and provides testable hypotheses to guide empirical work in this area. 
This theory may also have implications for our understanding of comparative institutions. In some countries, such as the United States, courts have high powers of review over administrative agencies. In many other countries, courts have minimal review powers over administrative agencies. Thus, the lobbying game, without the litigation game, may reflect a better understanding of lobbying in these countries. Finally, there are a number of countries, transition countries in particular, which are dealing with the development of their institutions. This model may help to shed on light of the impact of different designs of governmental institutions in these nations. Overall, this paper explains how the mere threat of litigation can affect the lobbying behavior of interest groups in bureaucracies.. 


\section{APPENDIX. PROOFS OF RESULTS}

Proof of Proposition 1. Using backward induction, first consider $R$ 's strategy. In this case, first solve for $x^{(}$in the case that $R$ rejects both $o_{A}$ and $o_{B}$. In this case, $R$ 's problem reduces to

$$
x^{(' \underset{x}{\operatorname{argmax}} \&|x|}
$$

which is simply $x^{('} 0$. Thus, $R$ will choose from the set $\epsilon_{A}, o_{B},(0,0)>$, by choosing the pair that maximizes her (expected) utility, which is precisely the conditions stated in (iii). Next, note that offering $y_{i}{ }^{\prime} w_{i}$ is a weakly dominant strategy for both $A$ and $B$ since $y$ is not an element of either player's utility function. Next, for any offer $o_{B}, A$ can offer a pair that makes $R$ better off, since $w_{A}>w_{B}$. If $B$ 's offer satisfies the constraint in (iii), then it is straightforward to show that $A$ 's best response is $o_{A}{ }^{\prime}\left(x_{B}^{o} \% v_{A} \& w_{B}, w_{A}\right)$. Given this response function, $B$ 's best response is to choose $x_{B}^{o}$ to maximize $x_{B} \& x_{B}^{o} \& w_{A} \% v_{B}$ which occurs at zero. This implies that $o_{B}^{(1}\left(0, w_{B}\right)$. Substituting this into $A$ 's best response function implies $o_{A}^{(1}\left(w_{A} \& w_{B}, w_{A}\right)$.

Proof of Lemma 1. Consider first if $x_{p}>q$. If there is no litigation, $A$ will be better off since $\&\left|x_{p} \& x_{A}\right|>\&\left|q \& x_{A}\right|$, so $A$ will not litigate. If there is litigation, however, $A$ will spend all remaining resources to defend the new policy since there is no cost to $z_{A}$ and $\Phi$ is decreasing in resources spent as defendants in the litigation stage. On the other hand, $B$ will be worse off if there is no litigation since $\&\left|x_{p} \& x_{B}\right|<\&\left|q \& x_{B}\right|$. By a similar argument for $A, B$ will therefore spend all resources to overturn the new policy. The same logic results if $A$ is substituted for $B$ and vice versa. 
Proof of Lemma 2. The first part follows from Proposition 1, by noting that adding the courts simply linearly tranforms A's choice problem when B has no resources. The second part follows from $q<0$ and the first part of the Lemma.

Proof of Proposition 2. Consider the problem given in (3).

Suppose $\mathrm{q} 0\left(x_{B}, 0\right)$ and $\mathrm{w}_{B}{ }^{\prime} 0$, and the following two conditions are satisfied:

$$
\begin{aligned}
& \text { (i) }\left(\Phi_{0} \& \Phi_{1}\right) q \frac{\alpha}{\beta} \% \frac{1}{\beta} \sqrt{\log k^{2}} \% x_{A}\left(1 \& \Phi_{1}\right)>w>\left(\Phi_{0} \& \Phi_{1}\right) q \frac{\alpha}{\beta} \% \frac{1}{\beta} \sqrt{\log k^{2}}>0 \\
& \text { (ii) } \beta>\frac{\sqrt{2 \pi}}{2 q}
\end{aligned}
$$

When constraints (ii) and (iii) do not bind, the first-order conditions for the Lagrangian $L$ (A1.1) are:

$$
\begin{aligned}
& y: \& \Phi_{1}^{\prime}(x \& q) \% \Phi_{1}^{\prime}(x \& p) \% \Phi_{1}^{\prime} q \% \Phi_{1}^{\prime} p \% \\
& \mathrm{x}^{o}:\left(1 \& \Phi_{1}\right) \& \lambda\left(1 \& \Phi_{1}\right) \\
& \lambda: \Phi_{1} q \&\left(1 \& \Phi_{1}\right) x^{o \%} \% \& \Phi_{0} q
\end{aligned}
$$

where $\Phi_{1}^{\prime)} \frac{M \Phi_{1}}{M}$. (A1.3) implies

$$
\lambda^{\prime} 1
$$

Substituting this result into (A1.2), we have

$$
\Phi_{1}^{) !} \& \frac{1}{2 q}
$$

Substituting for $\Phi_{1}^{\prime}$, we have

$$
\beta \varphi(\alpha \% \phi(y \& w))^{\prime} \& \frac{1}{2 q}
$$

where $\varphi($.$) is the probability density function for a standard normal random variable. This can be$ rewritten 


$$
\beta \frac{1}{\sqrt{2 \pi}} e^{\varepsilon \frac{1}{2}(\alpha \% \beta(y \delta w))^{2}} \cdot \& \frac{1}{2 q}
$$

Taking the logarithms of both sides we have:

$$
\& \frac{1}{2}(\alpha \%(y \& w))^{21} \log \left(\& \frac{\sqrt{2 \pi}}{2 \beta q}\right)
$$

Letting $k^{\prime} \frac{2 \beta q}{\sqrt{2 \pi}}$, we can rewrite (A1.5)

$$
(\alpha \%(y \& w))^{21} \log k^{2} .
$$

Solving for the roots of (A1.6), we have:

$$
\alpha \%(y \& w)^{\prime} \pm \sqrt{\left(\log k^{2}\right)} .
$$

Note that since $\beta>\frac{\sqrt{2 \pi}}{2 q}$, the right hand side of (A1.7) is real-valued, which is condition (ii) in the proposition. Taking the negative root, and solving for $y$, we have the first part of the proposition:

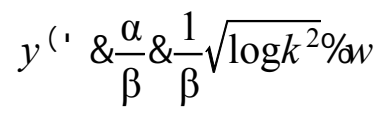

Substituting $y^{\prime}$ into equation (A1.4) and solving for $x^{o}$ yields

$$
x^{o(1} \frac{\left(\Phi_{1} \& \Phi_{0}\right) q \& \frac{\alpha}{\beta} \& \frac{1}{\beta} \log k^{2}}{1 \& \Phi_{1}} .
$$

Imposing constraints (ii) and (iii) on $y^{\prime}$ and $x^{o l}$ and solving for $w$ yields condition (i) in the proposition.

Proof of Corollary 1. By the Chain Rule, it is sufficient to show that $\frac{M^{o}}{M}>0$. Taking the derivative, we have:

$$
\frac{M^{o}}{M} \cdot \frac{\left(1 \& \Phi_{0}\right) \beta \varphi_{1} q \%\left(\& 1 \& \Phi_{1}\right) \% \phi \varphi_{1} y}{\left(1 \& \Phi_{1}\right)^{2}}
$$

which is positive by condition (i) in Proposition 2. 


\section{References}

Ainsworth, Scott (1993). "Regulating Lobbyists and Interest Group Influence," Journal of Politics 55:41-56.

Arnold, Douglas (1990). The Logic of Congressional Action. New Haven, CT: Yale University Press.

Austen-Smith, David (1993). "Information and Influence: Lobbying for Agendas and Votes." American Journal of Political Science 37: 799-834

Austen-Smith, David (1995). "Campaign Contributions and Access." American Political Science Review 89: 566-581.

Austen-Smith, David, and John R. Wright (1992). "Competitive Lobbying for a Legislator's Vote," Social Choice and Welfare 9: 229-257.

Austen-Smith, David, and John R. Wright (1994). "Counteractive Lobbying," American Journal of Political Science, 38: 25-44.

Banks, Jeffrey S. (1989). “Agency Budgets, Cost Information and Auditing.” American Journal of Political Science 33: 670-699.

Banks, Jeffrey S. and Barry R. Weingast (1992). "The Political Control of Bureaucracies under Asymmetric Information.” American Journal of Political Science 36: 509-524.

Baron, David P. (1994). Business and its Environment. Second Edition. Upper Saddle River, NJ: Prentice Hall.

Baron, David P. (1996). "The Non-Market Strategy System." Sloan Management Review 37: 73-85.

Baron, David P. (1999). "Integrated Market and Nonmarket Strategies in Client and Interest Group Politics." Business and Politics 1: 1-41..

Becker, Gary S. (1983). "A Theory of Competition Among Pressure Groups for Political Influence.” Quarterly Journal of Economics 98:3 371-400.

Bendor, Jonathan, and Terry M. Moe (1986). "Agenda Control, Committee Capture, and the Dynamics of Institutional Politics," American Political Science Review 80: 1187-1207.

Caldeira, Gregory A., and John R. Wright (1998). "Lobbying for Justice: Organized Interests, Supreme Court Nominations, and United States Senate," American Journal of Political Science 42: 499-523. 
Canes-Wrone, Brandice (1998). "Bureaucratic Decisions and the Composition of the Lower Courts," Department of Political Science Working Paper, Massachusetts Institute of Technology.

Cohen, Linda and Matthew Spitzer (1994). "Solving the Chevron Puzzle." Law and Contemporary Problems 57: 67-110.

Cortner, Richard C. (1968). "Strategies and Tactics of Litigants in Constitutional Cases," Journal of Public Law 17: 287-307.

Cross, Frank B. and Emerson H. Tiller (1998). "Judicial Partisanship and Obedience to Legal Doctrine: Whistleblowing on the Federal Courts of Appeal." Yale Law Journal 107: 2155-2176.

de Figueiredo, Rui J., Pablo Spiller, and Urbiztondo (1999). “An Informational Perspective on Administrative Procedures." Journal of Law, Economics, and Organization 15: 283-305.

de Figueiredo, John M. (1997). "The Politics of the Court and the Strategy of the Firm," Ph.D. Dissertation, University of California, Berkeley Haas School of Business.

Epstein, Lee (1985). Conservatives in Court. Knoxville: University of Tennessee Press.

Epstein, Lee, and Jack Knight (1995). "Positive Approaches to Supreme Court DecisionMaking," Paper presented at the annual meeting of the Midwest Political Science Association.

Ferejohn, John A., and Charles F. Shipan (1989). "Congressional Influence on the Bureaucracy," Journal of Law, Economics, and Organization 6: 1-27.

Galatner, Marc (1974). "Why Haves Come Out Ahead: Speculations on the Limits of Social Change," Law and Society Review 9: 95-160.

Grier, Kevin B., Michael C. Munger, and Brian E. Roberts (1994). "The Determinants of Industry Political Activity, 1978-1986," American Political Science Review 88: 911-926.

Groseclose, Timothy (1996). "An Examination of the Markets for Favors and Votes in Congress," Economic Inquiry.

Groseclose, Timothy, and James Snyder (1996). "Buying Supermajorities,” American Political Science Review, 90:303-15.

Hansen, John Mark (1991). Gaining Access: Congress and the Farm Lobby, 1919-1981. Chicago: University of Chicago Press.

Herring, Pendleton (1929). Group Representation Before Congress. Baltimore, MD: Johns Hopkins University Press. 
Kingdon, John W. (1981). Congressmen's Voting Decision, rev. ed. New York: Harper \& Row.

Krehbiel, Keith (1991). Information and Legislative Organization. Ann Arbor, MI: University of Michigan Press..

Latham, Earl (1952). "The Group Basis of Politics: Notes for a Theory," American Political Science Review 46: 376-397.

Lowi, Theodore J. (1979). The End of Liberalism, $2^{\text {nd }}$ Ed. New York: Norton.

Lupia, Arthur, and Mathew D. McCubbins (1994). "Designing Bureaucratic Regulation," Law and Contemporary Problems 57: 91-126.

Marks, Brian (1988). "A Model of Judicial Influence on Congressional Policymaking: Grove City College v. Bell," Political Science Working Paper, P-88-7, The Hoover Institution, Stanford University.

McCubbins, Mathew D., Roger Noll and Barry R. Weingast (1987). "Administrative Procedures as Instruments of Political Control.” Journal of Law, Economics, and Organization 3: 243-277.

McCubbins, Mathew D., Roger Noll and Barry R. Weingast (1989). "Structure and Process, Politics and Policy: Administrative Arrangements and the Political Control of Agencies."

Virginia Law Review 75: 431-482.

McCubbins, Mathew D., Roger Noll and Barry R. Weingast (1994). "Legislative Intent: The Use of Positive Political Theory in Statutory Interpretation." Law and Contemporary Problems 57: 337.

McCubbins, Mathew D., and Thomas Schwartz (1984). "Congressional Oversight Overlooked: Police Patrols v. Fire Alarms,” American Journal of Political Science, 29: 721-749.

McGuire, Kevin T., and Gregory A. Caldeira (1993). "Lawyers, Organized Interests, and the Law of Obscenity: Agenda Setting in the Supreme Court," American Political Science Review 87: 717-726.

Milbraith, Lester W. (1963). The Washington lobbyists. Chicago: Rand McNally

Olson, Mancur (1965). The Logic of Collective Action. Cambridge, MA: Harvard University Press.

Olson, Susan (1990). "Interest Group Litigation in Federal District Court: Beyond Political Disadvantage Theory," Journal of Politics 52: 854-882.

Peltzman, Samuel (1976). “Toward a More General Theory of Regulation.” Journal of Law and 
Economics 19: 211-240.

Riker, William H., and Barry R. Weingast (1986). "The Political and Economic Consequences of Judicial Deference to Legislatures,” Mimeo, Washington University-St. Louis.

Rubin, Paul H., Christopher Curran, and John F. Curran (1999). "Litigation versus Legislation: Forum Shopping by Rent-Seekers," Department of Economics Working Paper, Emory University.

Schwartz, Edward P., Pablo T. Spiller and Santiago Urbiztondo (1994). "A Positive Theory of Legislative Intent." Law and Contemporary Problems 57: 51-74.

Segal, Jeffrey A. (1997). "Separation-of-Powers Games in the Positive Theory of Congress and the Courts," American Political Science Review 91: 28-44.

Segal, Jeffery A., and Harold J. Spaeth (1993). The Supreme Court and the Attitudinal Model. Cambridge, MA: Harvard University Press.

Snyder, James (1990). "Campaign Contributions as Investments: The U.S. House of Representatives, 1980-1986,” Journal of Political Economy 98: 1195-1227.

Snyder, James (1991). “On Buying Legislatures,” Economics and Politics 3: 93-109.

Snyder, James (1992). "Long-Term Investing in Politicians; Or, Give Early, Give Often" Journal of Law \& Economics 35: 15-43.

Songer, Donald R., and Reginald S. Sheehan (1992). "Who Wins on Appeal? Upperdogs and Underdogs in the United States Courts of Appeals," American Journal of Political Science 36: 235-258.

Spiller, Pablo T (1992). “Agency Discretion Under Judicial Review.” Mathematical and Computer Modelling 16: 185.

Spiller, Pablo T. and Rafael Gely (1992). "Congressional Control of Judicial Independence: The Determinants of U.S. Supreme Court Labor-Relations Decisions, 1949-1988." Rand Journal of Economics 23: 463-492.

Spiller, Pablo T. and Matthew Spitzer (1992). “Judicial Choice of Legal Doctrines.” Journal of Law, Economics and Organization 8: 8-46.

Stratmann, Thomas (1992). “Are Contributors Rational? Untangling Strategies of Political Action Committees," Journal of Political Economy 100: 647-664.

Stratmann, Thomas (1998). "The market for congressional votes: Is timing of contributions everything?” Journal of Law \& Economics, 41:85-113. 
Stigler, George J. (1971). "The Theory of Economic Regulation.” Bell Journal of Economics and Management Science 2:3-21.

Tiller, Emerson H. "Controlling Policy by Controlling Process: Judicial Influence on Regulatory Decision Making." Journal of Law, Economics and Organization 14: 114-135.

Tiller, Emerson H. and Pablo T. Spiller (1999). "Strategic Instruments: Legal Structure and Political Games in Administrative Law," Journal of Law, Economics and Organization 15.

Truman, David (1971). The Governmental Process, $2^{\text {nd }}$ Edition. New York: Knopf.

Tullock, Gordon (1980). “Efficient Rent-Seeking.” In James M. Buchanan, R. D. Tollison and Gordon Tullock, eds. Toward a Theory of the Rent-Seeking Society. College Station: Texas A\&M Press. 97-112.

Wheeler, Stanton, Bliss Cartwright, Robert Kagan, and Lawrence Friedman (1987). "Do the 'Haves' Come Out Ahead? Winning and Losing in the State Supreme Courts, 1870-1970," Law and Society Review 21: 403-445. 


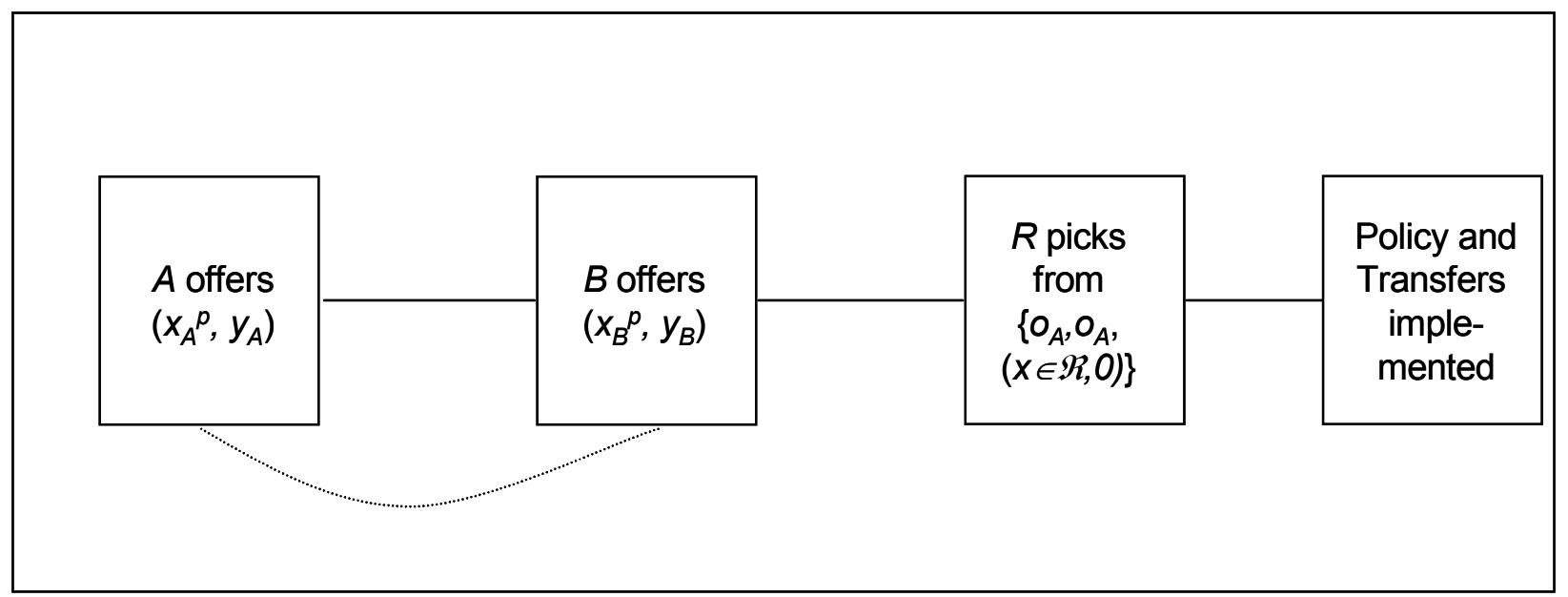

Figure 1. Sequence of Play in the Lobbying Game 


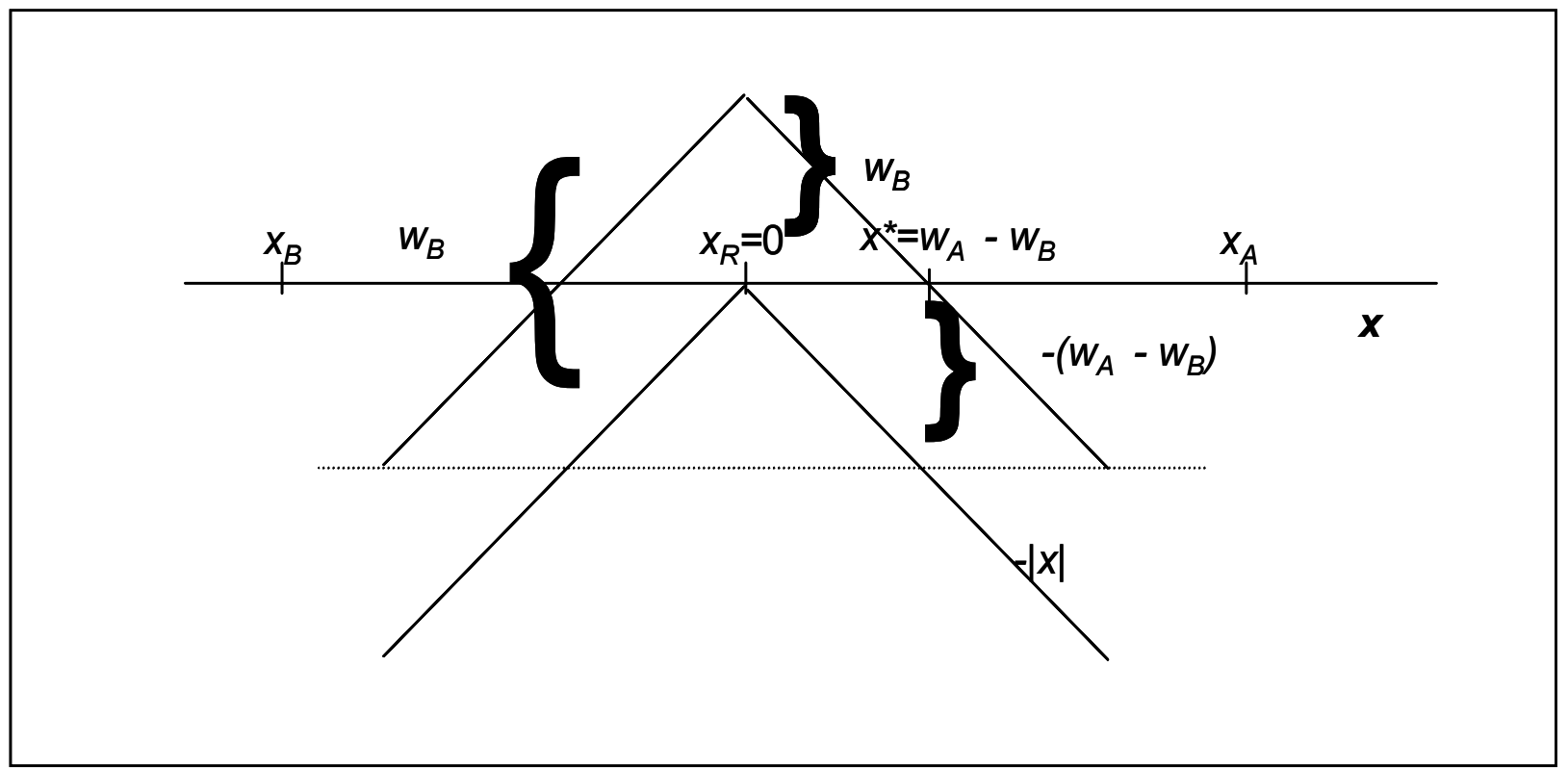

Figure 2. Equilibrium to the Lobbying Game 


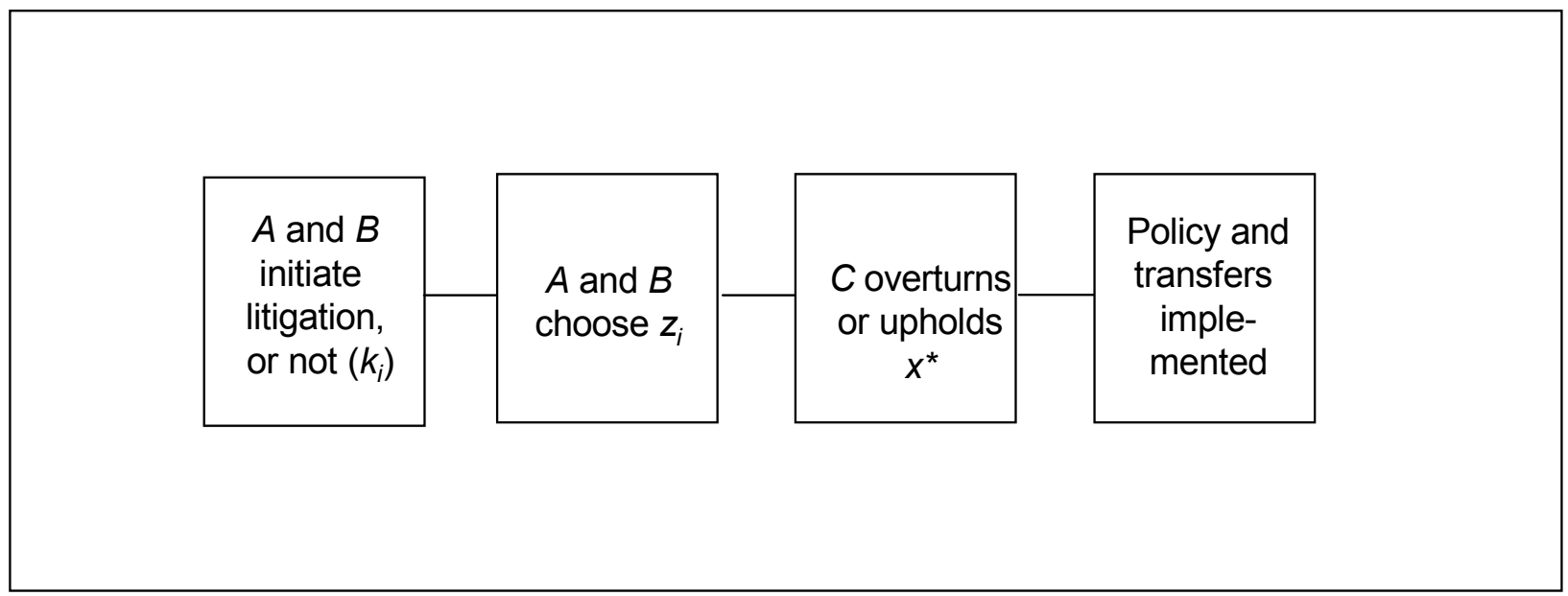

Figure 3. Sequence of Play in the Litigation Game 


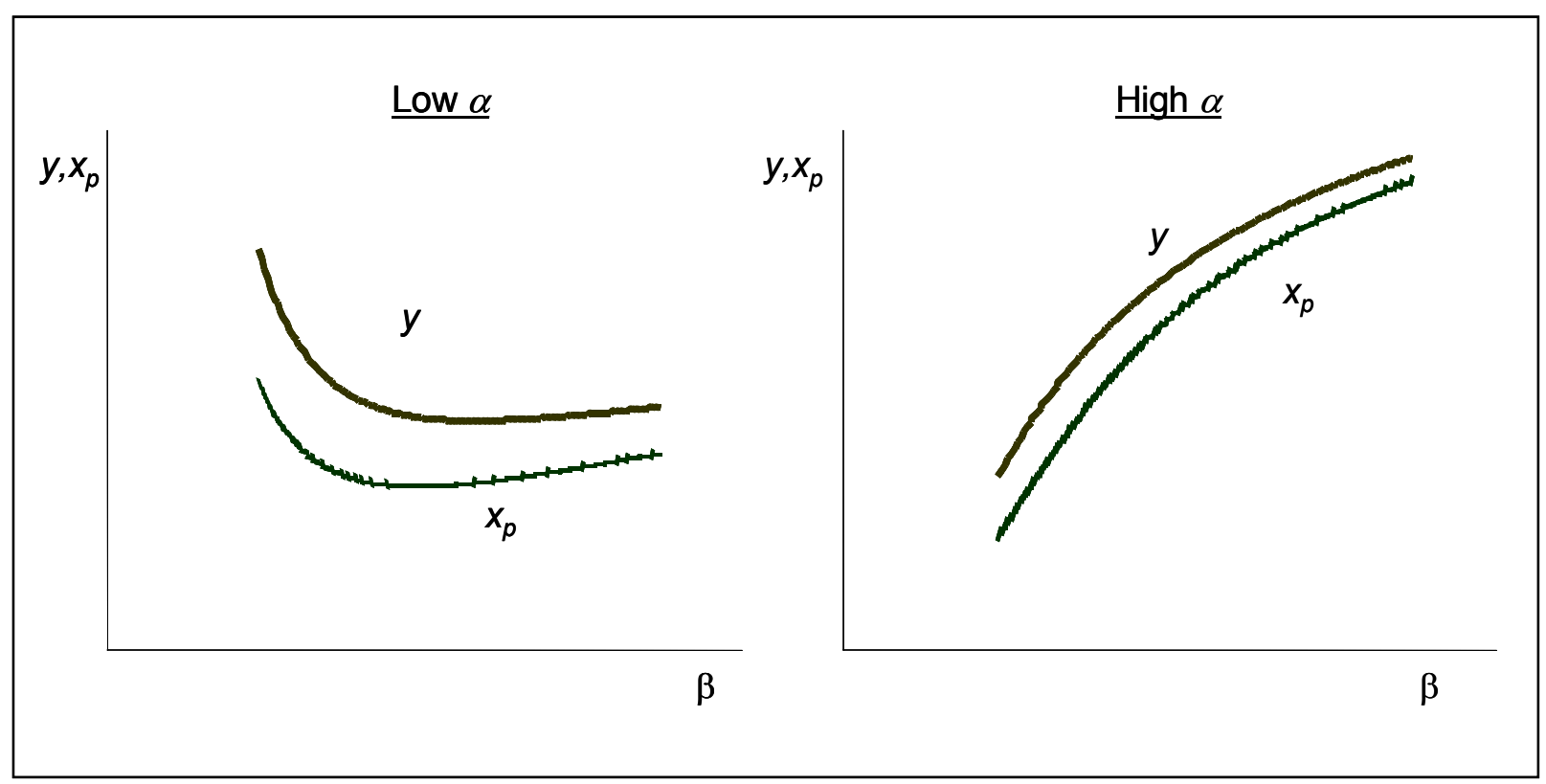

Figure 4. Effect of $\beta$ on Equilibrium Offers 